\title{
The addition of hemiarch replacement to aortic root surgery does not affect safety
}

Sukit Christopher Malaisrie, MD, ${ }^{a}$ Brett F. Duncan, MD, ${ }^{a}$ Chris K. Mehta, MD, ${ }^{a}$ Mitesh V. Badiwala, MD, ${ }^{a}$ Dan Rinewalt, MD, ${ }^{\mathrm{a}}$ Jane Kruse, RN, BSN, ${ }^{\mathrm{b}}$ Zhi Li, MS, ${ }^{\mathrm{b}}$ Adin-Christian Andrei, PhD, ${ }^{\mathrm{b}}$ and Patrick M. McCarthy, MD

\begin{abstract}
Objectives: A hemiarch reconstruction, using deep hypothermic circulatory arrest, is the conventional approach for proximal aortic arch reconstruction, but it carries risks of neurologic events and coagulopathy. The addition of a hemiarch reconstruction to an aortic root replacement may prevent future aortic arch pathology. Outcomes of this approach at a tertiary care institution were examined to determine whether the addition of a hemiarch reconstruction to an aortic root replacement conferred any additional risk.
\end{abstract}

Methods: A total of 384 patients underwent an aortic root replacement between April 2004 and June 2012. Of them, 177 (46\%) had hemiarch replacement. Propensity score matching yielded 133 pairs of patients receiving hemiarch and non-hemiarch.

Results: Sinus segment diameter was similar between groups; ascending aortic diameter was greater in the hemiarch group (median 50 vs $44 \mathrm{~mm} ; P<.001$ ). The hemiarch group had longer perfusion (median 186 vs 120.5 minutes; $P<.001$ ) and crossclamp times (median 140 vs 104 minutes; $P<.001$ ); median circulatory arrest was 13 minutes. There was no difference, hemiarch versus no hemiarch, in 30 -day mortality $(3.0 \%$ vs $1.5 \% ; P=.41)$, stroke $(2.3 \%$ vs $4.5 \% ; P=.31)$, reoperation for bleeding $(11 \%$ vs $10 \% ; P=.84)$, or overall survival (5-year $88.0 \%$ [95\% confidence interval, 81.9-94.0] vs $91.4 \%[95 \%$ confidence interval, 85.8-96.9], $P=.24$ ).

Conclusions: In this series, aortic root replacement \pm hemiarch reconstruction had low mortality. Addition of hemiarch replacement extended perfusion times but not at the expense of safety. Hemiarch reconstruction should be performed when the aortic root aneurysm extends into the distal ascending aorta. (J Thorac Cardiovasc Surg 2015;150:118-24)

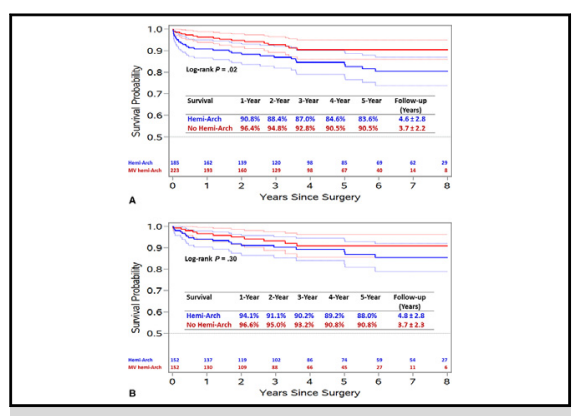

Kaplan-Meier estimates of medium-term overall survival in the original groups (A) and the PS-matched groups (B). Kaplan-Meier survival of original and matched groups for ARR alone versus ARR/hemiarch.

\section{Central Message}

In this series, ARR with and without hemiarch reconstruction had low mortality. Addition of hemiarch replacement extended perfusion times but not at the expense of increased stroke or bleeding complications. Hemiarch reconstruction should be performed when the aortic root aneurysm extends into the distal ascending aorta.

\section{Perspective}

A threshold of $4.0 \mathrm{~cm}$ for distal ascending aorta or proximal arch dilatation may be reasonable for the addition of a hemiarch procedure. The added operative time should be balanced with the risk of leaving diseased aortic tissue. The addition of the hemiarch is a safe strategy to avoid disease progression and should be considered at the time of ARR. Our study found no difference in operative mortality, midterm all-cause mortality, or significant morbidity with the addition of a hemiarch reconstruction.

See Editorial Commentary page 125.

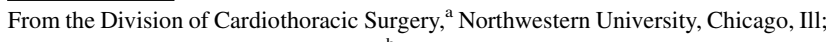
and Bluhm Cardiovascular Institute, ${ }^{\mathrm{b}}$ Northwestern Medicine, Chicago, Ill.

Read at The American Association for Thoracic Surgery Aortic Symposium, New York, New York, April 24-25, 2014.

Received for publication Dec 22, 2014; revisions received Feb 27, 2015; accepted for publication March 15, 2015; available ahead of print April 18, 2015.

Address for reprints: Sukit Christopher Malaisrie, MD, Division of Cardiac Surgery, Bluhm Cardiovascular Institute, 201 E Huron St, Suite 11-140, Chicago, IL 60611-2908 (E-mail: cmalaisr@nm.org).

$0022-5223 / \$ 36.00$

Copyright (c) 2015 by The American Association for Thoracic Surgery

http://dx.doi.org/10.1016/j.jtcvs.2015.03.020
丹 Supplemental material is available online.

Aortic root replacement (ARR) using the modified Bentall procedure is performed using a composite valve graft (valved conduit) to repair aortic root aneurysms with aortic valve disease. Although ARR addresses aortic root and 


\section{Abbreviations and Acronyms}

$\mathrm{ARR}=$ aortic root replacement

DHCA $=$ deep hypothermic circulatory arrest

PS $=$ propensity score

ascending aorta aneurysms, it does not address aortic pathology that extends distally into the aortic arch. There is a risk of progression of aortopathy leading to an aortic arch aneurysm if the aneurysm is not fully resected. ${ }^{1,2}$ Proximal aortic arch reconstruction using the hemiarch technique is the conventional approach to treat aneurysms of the distal ascending aorta and proximal arch. This may be used in combination with an ARR to extend the aortic aneurysm repair to resect all aneurysmal tissue. However, the addition of the hemiarch procedure may confer additional risk because of the need for deep hypothermic circulatory arrest (DHCA). ${ }^{3}$ Durations of DHCA exceeding 25 to 50 minutes have been associated with an increased risk of neurologic dysfunction and hypothermia-induced coagulopathy. ${ }^{4-6}$ Given the added complexity of this additional operation, there has long been debate regarding the appropriate extent of aortic reconstruction that should be undertaken in patients undergoing ARR for aortic root aneurysms. $^{7}$ The 2010 Guidelines for the Diagnosis and Management of Patients with Thoracic Aortic Disease do not address the extent of aortic reconstruction with ARR for the prevention of future aortic pathology. ${ }^{8,9}$ The present study compares outcomes from ARR using the modified Bentall procedure with and without a concomitant hemiarch reconstruction.

\section{MATERIALS AND METHODS \\ Patient Selection}

Data for this project were obtained from the Cardiovascular Research Database in the Clinical Trial Unit of the Bluhm Cardiovascular Institute at Northwestern Memorial Hospital. This database was approved by the Institutional Review Board at Northwestern University (project \#STU00012288). Any subjects refusing participation in the project were not included in the analysis. From April 2004 to June 2012, we retrospectively identified 384 patients who underwent ARR for aortic root aneurysm at a single tertiary care institution (Northwestern Memorial Hospital, Chicago, Ill). There were 177 patients $(46 \%)$ who received a concomitant hemiarch replacement for involvement of aortopathy into the proximal aortic arch at the time of the ARR. Patients with transcatheter aortic valve replacement, total arch replacement, aortic dissections, or prior homografts were excluded. Selected preoperative characteristics are summarized in Table 1.

\section{Operative Technique}

All patients underwent an ARR using a composite valve graft to replace the proximal ascending aorta and aortic valve. This was accomplished by median sternotomy; cardiopulmonary bypass was achieved by femoral or axillary arterial cannulation and right atrial venous cannulation. Hemiarch reconstruction was achieved using DHCA. Patients were cooled to $18^{\circ} \mathrm{C}$ to $22^{\circ} \mathrm{C}$ measured by nasopharyngeal temperature. Cerebral protection was achieved by antegrade or retrograde cerebral perfusion. Near infrared spectroscopy was used by some staff for cerebral monitoring. Systemic steroids and ice packing to the head were used as adjuncts for hypothermic arrest. The aortic valve and aortic root were excised after mobilizing the coronary arteries as buttons. The composite valve graft was constructed by sewing a stented bovine pericardial valve to the bottom of woven Dacron graft. The composite valve graft was then secured to the aortic annulus with interrupted, noneverting, horizontal mattress stitches. The coronary arteries were anastomosed to the body of the graft as buttons. The decision to perform a hemiarch replacement was at the discretion of the surgeon. Hemiarch replacement involved resection of the aorta from the base of the innominate artery to the lesser curve and replacement with a Dacron graft. Our practice is to replace the distal ascending aorta and proximal transverse arch when the diameter of the proximal transverse arch is $4.0 \mathrm{~cm}$ or greater (Figure 1). For those patients with a proximal aortic arch diameter less than $4.0 \mathrm{~cm}$, only an ARR was performed unless no neck was available proximal to the innominate artery for safe placement of an aortic crossclamp. These cases were also treated with a hemiarch procedure.

\section{Follow-up}

All patient data were prospectively gathered during regular follow-up visits. Mean follow-up was $4.8 \pm 2.8$ years in the ARR/hemiarch group and $3.8 \pm 2.2$ years in the ARR alone group $(P<.001)$.

\section{Statistical Analysis}

To reduce potential confounding due to baseline imbalances between the ARR alone and the ARR/hemiarch groups, propensity score (PS) matching methods were used. Groups were compared using 1-to-1 PS matching based on a greedy algorithm with a caliper of size 0.2 logit PS standard deviation units, adjusting for the following factors: age, gender, Ambler score, body surface area (meters squared), coronary artery disease, family history of coronary artery disease, diabetes, hypercholesterolemia, hypertension, chronic obstructive pulmonary disease, prior congestive heart failure, prior myocardial infarction, cardiovascular disease, cerebrovascular accident, prior valve surgery, prior cardiovascular intervention, repeat sternotomy, mitral valve surgery, aortic stenosis, elective status, New York Heart Association functional class III/IV, and preoperative medications (beta-blockers, statins).

Baseline demographics for the original and PS-matched groups are summarized in Table 1. Continuously distributed variables are reported as mean \pm standard deviation or median (first quartile Q1, third quartile Q3). Binary or discrete variables are presented using counts and percentages. The adequacy of between-groups balance in each baseline characteristic used to create the PS model was assessed using standardized differences. ${ }^{10}$ The standardized differences are depicted in Figure 2 (orange for the original groups; violet for the PS-matched groups) and numerical values can be seen in Table E1. Further visual confirmation of the PS-matching quality was obtained using beanplots (kernel-smoothed histograms), which are shown in Figure E1.

Postsurgery medium-term overall survival was summarized using Kaplan-Meier curves, and gender comparisons were based on the log-rank test (Figure 3). One-way analysis of variance or the Kruskal-Wallis test was used to compare continuously distributed variables. The chi-square or Fisher exact test was used to compare discrete variables. Statistical significance was declared at 2-sided 5\% alpha level, and there were no multiplicity adjustments. Statistical analyses were performed using SAS 9.3 software (SAS Institute Inc, Cary, NC) and R 3.1.1 (R Development Core Team, 2011).

\section{RESULTS \\ Original Groups}

In the original groups, patients in the ARR alone group were borderline significantly younger (mean age of 
TABLE 1. Baseline characteristics of original and propensity score-matched groups

\begin{tabular}{|c|c|c|c|c|c|c|}
\hline \multirow[b]{2}{*}{ Variable } & \multicolumn{2}{|c|}{ Original groups } & \multirow[b]{2}{*}{$\begin{array}{c}P \\
\text { value }\end{array}$} & \multicolumn{2}{|c|}{ PS-matched groups } & \multirow[b]{2}{*}{$\begin{array}{c}P \\
\text { value }\end{array}$} \\
\hline & $\begin{array}{c}\text { ARR alone } \\
(\text { no hemiarch })(N=207)\end{array}$ & $\begin{array}{l}\text { ARR/hemiarch } \\
\quad(\mathbf{N}=\mathbf{1 7 7})\end{array}$ & & $\begin{array}{c}\text { ARR alone } \\
(\text { no hemiarch })(N=133)\end{array}$ & $\begin{array}{c}\text { ARR/hemiarch } \\
\quad(\mathbf{N}=\mathbf{1 3 3})\end{array}$ & \\
\hline Age (y) & $55.1 \pm 13.3$ & $57.8 \pm 13.1$ & .05 & $57.5 \pm 12.3$ & $56.2 \pm 12.9$ & .41 \\
\hline $\operatorname{BSA}\left(\mathrm{m}^{2}\right)$ & $2.1 \pm 0.3$ & $2.1 \pm 0.3$ & .45 & $2.1 \pm 0.3$ & $2.1 \pm 0.2$ & .87 \\
\hline Ejection fraction & $60.0(55.0-63.0)$ & $60.0(55.0-63.0)$ & .85 & $60.0(55.0-65.0)$ & $60.0(55.0-63.0)$ & .97 \\
\hline Sinus segment diameter $(\mathrm{mm})$ & $45.0(40.0-50.0)$ & $44.0(40.0-50.0)$ & .98 & $45.0(40.0-50.0)$ & $44.0(40.0-51.0)$ & .92 \\
\hline Ascending aortic diameter (mm) & $44.0(40.0-48.0)$ & $50.0(46.0-54.0)$ & $<.001$ & $44.0(41.0-48.0)$ & $50.0(46.0-54.0)$ & $<.001$ \\
\hline Maximum aortic diameter $(\mathrm{mm})$ & $47.0(44.0-52.0)$ & $52.5(50.0-56.0)$ & $<.001$ & $47.5(44.0-52.0)$ & $52.0(49.0-55.0)$ & $<.001$ \\
\hline Female gender & $36(17 \%)$ & $39(22 \%)$ & .25 & $29(22 \%)$ & $26(20 \%)$ & .65 \\
\hline Hypertension & $119(57 \%)$ & $115(65 \%)$ & .13 & $82(62 \%)$ & $78(59 \%)$ & .62 \\
\hline Cerebrovascular disease & $15(7 \%)$ & $8(5 \%)$ & .26 & $5(4 \%)$ & $8(6 \%)$ & .39 \\
\hline Repeat sternotomy & $36(17 \%)$ & $33(19 \%)$ & .75 & $21(16 \%)$ & $21(16 \%)$ & 1.00 \\
\hline Elective surgery & $196(95 \%)$ & $162(92 \%)$ & .22 & $124(93 \%)$ & $126(95 \%)$ & 61 \\
\hline
\end{tabular}

$P S$, Propensity score; $A R R$, aortic root replacement; $B S A$, body surface area.

$55.1 \pm 13.3$ years) compared with $57.8 \pm 13.1$ years in the ARR/hemiarch group $(P=.05)$. Patients were predominantly male: $83 \%$ in the ARR alone group and $78 \%$ in the ARR/hemiarch group $(P=.25)$. In the ARR alone group, $95 \%$ of operations were performed electively compared with $92 \%$ in the ARR/hemiarch group $(P=.22)$. Indications for emergency or urgent procedures included acute myocardial infarction, congestive heart failure, and valve dysfunction. There were $14 \%$ of patients in the ARR alone group and $20 \%$ of patients in

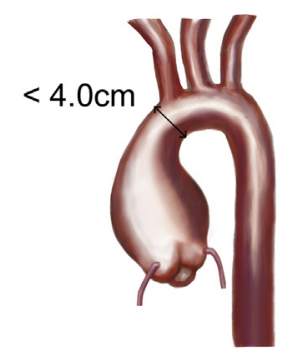

A

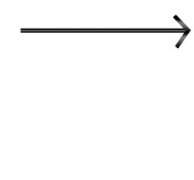

B No Hemi-arch

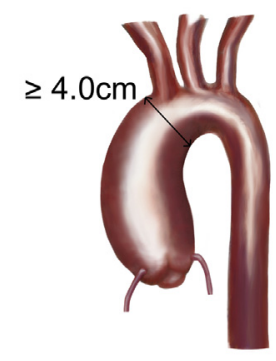

C
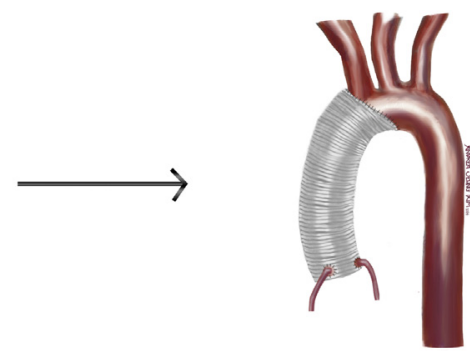

D Hemi-arch

FIGURE 1. Operative technique. The decision to perform a hemiarch, replacing the distal ascending aorta and proximal transverse arch, when the diameter of the proximal transverse arch is $4.0 \mathrm{~cm}$ or more. A, Aortic root and ascending aortic aneurysm, proximal arch less than $4.0 \mathrm{~cm}$. $\mathrm{B}$, ARR without hemiarch. C, Aortic root and ascending aortic aneurysm, proximal arch $4.0 \mathrm{~cm}$ or more. D, ARR with hemiarch. the ARR/hemiarch group who underwent concomitant coronary artery bypass grafting. Median ascending aortic diameter was significantly smaller in the ARR alone group

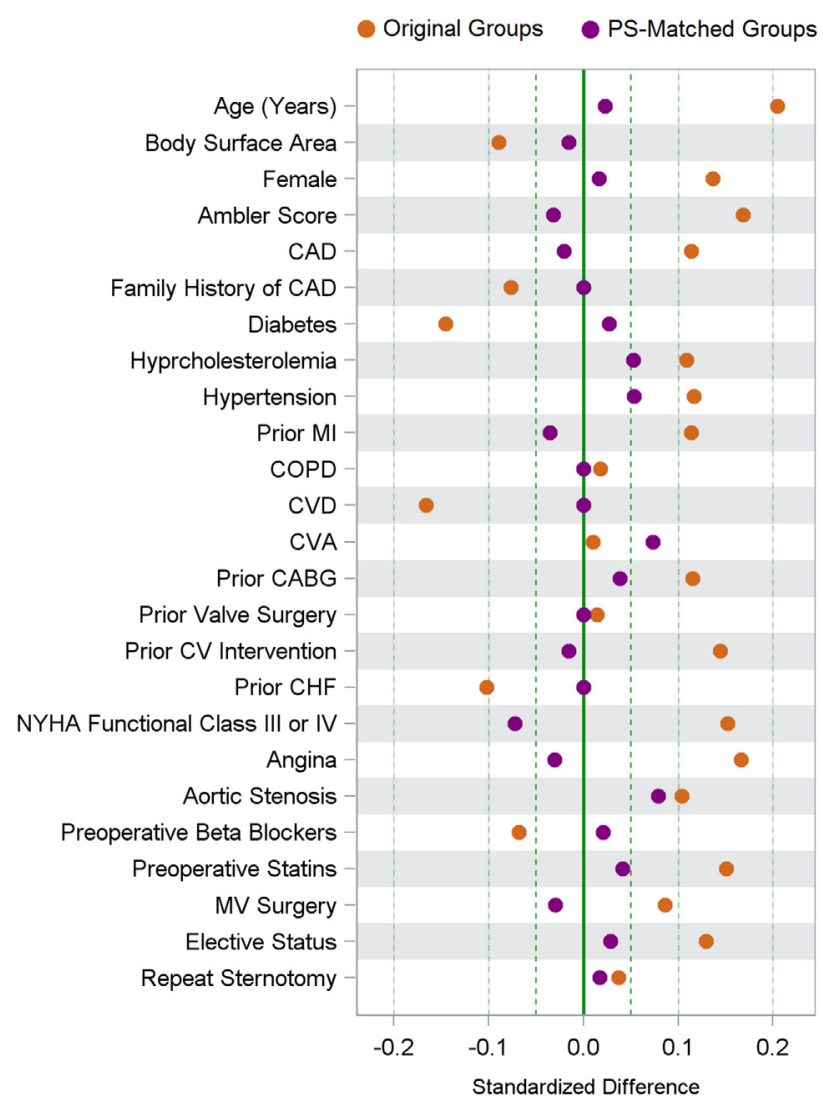

FIGURE 2. Standardized differences in the baseline covariates used in the construction of the PS model. Orange dots indicate the respective standardized difference in the original groups, and violet corresponds to the PS-matched groups. PS, Propensity score; $C A D$, coronary artery disease; $M I$, myocardial infarction; $C O P D$, chronic obstructive pulmonary disease; $C V D$, cardiovascular disease; $C V A$, cerebrovascular accident; $C A B G$, coronary artery bypass grafting; $C V$, cardiovascular; $C H F$, congestive heart failure; $N Y H A$, New York Heart Association. 

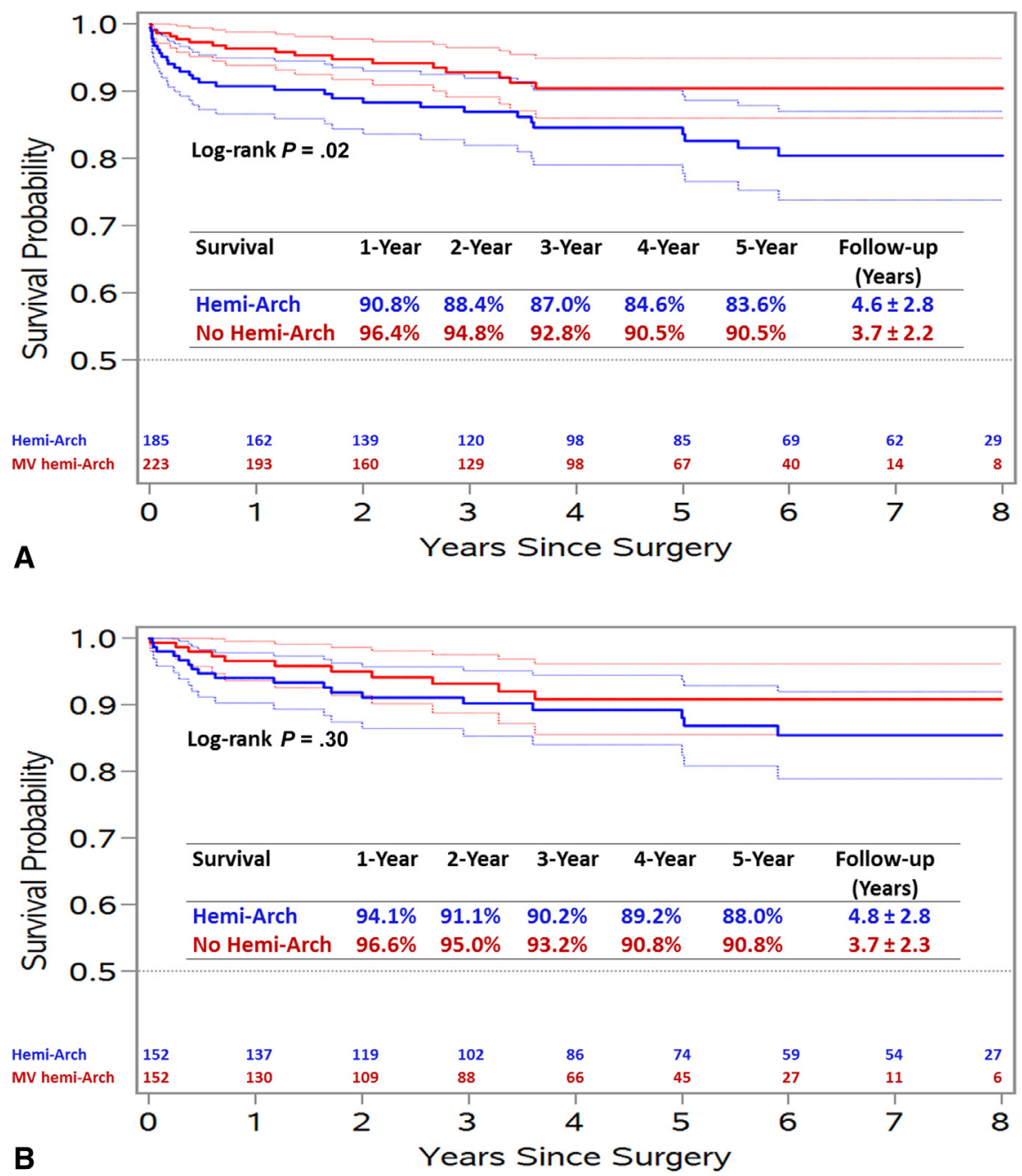

FIGURE 3. Kaplan-Meier estimates of medium-term overall survival in the original (A) and PS-matched (B) groups. Corresponding pointwise $95 \%$ CIs are depicted using dotted lines. MV, Mitral valve.

compared with the ARR/hemiarch group (44 vs $50 \mathrm{~mm}$, $P<.001)$. There was no significant difference in sinus segment diameter (median $45 \mathrm{~mm}$ in ARR alone vs $44 \mathrm{~mm}$ in ARR/hemiarch, $P=.98$ ). The presence of a bicuspid aortic valve was not significantly different between groups with a bicuspid valve in $60 \%$ (124/207) of the ARR alone group and $52 \%(92 / 177)$ of the ARR/hemiarch group $(P=.12)$. One patient $(0.5 \%, 1 / 207$ and $0.6 \%, 1 / 177$, $P=.91)$ in each group had Marfan syndrome, and 8 patients $(3.9 \%, 8 / 207)$ in the ARR alone and 3 patients $(1.7 \%$, $3 / 177)$ in the ARR/hemiarch groups had other connective tissue disorders $(P=.20)$.

Operative mortality was $1.4 \%(3 / 207)$ in the ARR alone group versus $3.4 \%$ (6/177 patients) in the ARR/hemiarch group $(P=.21)$. The 30 -day mortality was $1.4 \%(3 / 207)$ in the ARR alone group versus $2.8 \%$ (5/177 patients) in the ARR/hemiarch group $(P=.35)$. A bioprosthetic valve was used in 94\% (194/207) and 89\% (158/177) of patients in the ARR alone and ARR/hemiarch groups, respectively.
Retrograde cerebral perfusion was used in $89 \%$ (158/177) of patients in the ARR/hemiarch group, and antegrade cerebral perfusion was used in $11 \%$ of patients $(19 / 177)$. Intraoperative blood product use was lower in the ARR alone group, with $51 \%(106 / 207)$ of patients receiving blood products versus $72 \%(128 / 177)$ of patients in the ARR/hemiarch group $(P<.001)$. There was significantly more units of red blood cells transfused in patients in the ARR/hemiarch group than in patients in the ARR alone group $(2.6 \pm 5.4$ vs $1.4 \pm 2.3, P=.035)$, but there was no difference in units of platelets, fresh-frozen plasma, or cryoprecipitate transfused. Postoperative characteristics for the original groups are shown in Table 2. There was no difference in postoperative length of stay (median 5 vs 6 days, $P=.10)$ or intensive care unit stay (29.9 vs 34.5 hours, $P=.43$ ) between the ARR and ARR/hemiarch groups. There was also no difference in rates of reoperation for bleeding, postoperative stroke, prolonged mechanical ventilation, or acute renal failure requiring temporary 
TABLE 2. Perioperative characteristics and outcomes of original groups

\begin{tabular}{|c|c|c|c|}
\hline Variable & $\begin{array}{c}\text { ARR alone } \\
\text { (no hemiarch) } \\
(\mathbf{N}=\mathbf{2 0 7})\end{array}$ & $\begin{array}{l}\text { ARR/hemiarch } \\
\qquad(\mathbf{N}=\mathbf{1 7 7})\end{array}$ & $\begin{array}{c}P \\
\text { value }\end{array}$ \\
\hline Total ICU LOS (h) & $29.9(24.5-64.0)$ & $34.5(24.0-67.7)$ & .43 \\
\hline Postoperative LOS (d) & $5.0(5.0-7.0)$ & $6.0(5.0-8.0)$ & .10 \\
\hline Total hospital LOS (d) & $6.0(5.0-7.0)$ & $6.0(5.0-8.0)$ & .019 \\
\hline Complications & $79(38 \%)$ & $88(50 \%)$ & .023 \\
\hline Reoperation for bleeding & $19(9 \%)$ & $20(11 \%)$ & .49 \\
\hline $\begin{array}{l}\text { Reoperation for valve } \\
\text { dysfunction }\end{array}$ & $0(0 \%)$ & $1(0.5 \%)$ & .28 \\
\hline $\begin{array}{l}\text { Reoperation for bypass } \\
\text { graft failure }\end{array}$ & $0(0 \%)$ & $2(1.1 \%)$ & .13 \\
\hline $\begin{array}{l}\text { Reoperation for noncardiac } \\
\text { reason }\end{array}$ & $7(3.3 \%)$ & $9(5 \%)$ & .41 \\
\hline Postoperative stroke $>24 \mathrm{~h}$ & $6(2.8 \%)$ & $5(2.8 \%)$ & .97 \\
\hline Transient ischemic attack & $0(0 \%)$ & $1(0.5 \%)$ & .28 \\
\hline Prolonged ventilation $>24 \mathrm{~h}$ & $15(7 \%)$ & $22(12 \%)$ & .09 \\
\hline Renal failure & $7(3.3 \%)$ & $7(3.9 \%)$ & .77 \\
\hline Dialysis required & $4(1.9 \%)$ & $6(3.4 \%)$ & .37 \\
\hline Postoperative atrial fibrillation & $47(23 \%)$ & $41(23 \%)$ & .92 \\
\hline Aortic dissection & $0(0 \%)$ & $1(0.6 \%)$ & .28 \\
\hline 30-d mortality & $3(1.4 \%)$ & $5(2.8 \%)$ & .35 \\
\hline
\end{tabular}

hemodialysis. There was no difference in the number of patients who received blood product transfusions postoperatively $(42 \%, 87 / 207$ vs $48 \%, 85 / 177, P=.24)$. There was no difference in units of red blood cells, plasma, or platelets transfused; however, there were significantly more units of cryoprecipitate transfused in the ARR/hemiarch group $(0.2 \pm 0.6$ vs $1.2 \pm 3.4$, $P=.007$ ). Medium-term overall survival (Figure 3, A) was significantly higher (log-rank $P=.03$ ) in the ARR group $(92.1 \%, 95 \% \mathrm{CI}$ at 5 years, $87.8-96.3)$ than in the ARR/hemiarch group $(85.8 \%, 95 \% \mathrm{CI}$ at 5 years, 80.2-91.4).

\section{Propensity Score-Matched Groups}

PS matching resulted in 133 pairs of patients receiving ARR alone and ARR with hemiarch reconstruction. As shown in Figure 2, PS matching leads to lower standardized differences, compared with those observed in the original groups. Figure E1 displays similar PS distributions in the PS-matched groups.

The mean age of the ARR alone group was $57.5 \pm 12.3$ years, similar to that of the ARR/hemiarch group $(56.2 \pm 12.9$ years $)$, and the majority of patients were men $(78 \%$ ARR alone and $80 \%$ in the ARR/hemiarch). Operations were performed on an elective basis in $93 \%$ of patients in the ARR alone group and in $95 \%$ of the patients in the ARR/hemiarch group. The median ascending aortic diameter was significantly lower in the ARR alone group (44 vs $50 \mathrm{~mm}, P<.001$ ) compared with the ARR/hemiarch group. There were no significant
TABLE 3. Perioperative characteristics and outcomes of propensity score-matched groups

\begin{tabular}{|c|c|c|c|}
\hline Variable & $\begin{array}{c}\text { ARR alone } \\
\text { (no hemiarch) } \\
(\mathbf{N}=\mathbf{1 3 3})\end{array}$ & $\begin{array}{l}\text { ARR/hemiarch } \\
\quad(\mathbf{N}=\mathbf{1 3 3})\end{array}$ & $\begin{array}{c}P \\
\text { value } \\
\end{array}$ \\
\hline Total ICU LOS (h) & $29.4(23.4-66.1)$ & $31.6(23.8-51.7)$ & .91 \\
\hline Postoperative LOS (d) & $5.0(5.0-7.0)$ & $6.0(5.0-7.0)$ & .70 \\
\hline Total hospital LOS (d) & $6.0(5.0-8.0)$ & $6.0(5.0-8.0)$ & .50 \\
\hline Complications & $49(36.8 \%)$ & $62(46.6 \%)$ & .11 \\
\hline Reoperation for bleeding & $13(9.8 \%)$ & $14(10.5 \%)$ & .84 \\
\hline $\begin{array}{l}\text { Reoperation for valve } \\
\text { dysfunction }\end{array}$ & $0(0 \%)$ & $1(0.8 \%)$ & .32 \\
\hline $\begin{array}{l}\text { Reoperation for bypass } \\
\text { graft failure }\end{array}$ & $0(0 \%)$ & $1(0.8 \%)$ & .32 \\
\hline $\begin{array}{l}\text { Reoperation for other cardiac } \\
\text { reason }\end{array}$ & $2(1.5 \%)$ & $3(2.3 \%)$ & .65 \\
\hline Postoperative stroke $>24 \mathrm{~h}$ & $6(4.5 \%)$ & $3(2.3 \%)$ & .31 \\
\hline Transient ischemic attack & $0(0 \%)$ & $0(0 \%)$ & - \\
\hline Prolonged ventilation $>24 \mathrm{~h}$ & $10(7.5 \%)$ & $11(8.3 \%)$ & .82 \\
\hline Renal failure & $6(4.5 \%)$ & $3(2.3 \%)$ & .31 \\
\hline Dialysis required & $3(2.3 \%)$ & $2(1.5 \%)$ & .65 \\
\hline Postoperative atrial fibrillation & $28(21.1 \%)$ & $29(21.8 \%)$ & .88 \\
\hline Aortic dissection & $0(0 \%)$ & $1(0.8 \%)$ & .32 \\
\hline 30-d mortality & $2(1.5 \%)$ & $4(3.0 \%)$ & .41 \\
\hline
\end{tabular}

$A R R$, Aortic root replacement; ICU, intensive care unit; $L O S$, length of stay.

differences in sinus segment diameter (median $45 \mathrm{~mm}$ ARR alone vs $44 \mathrm{~mm}$ ARR/hemiarch, $P=.92$ ). Bicuspid aortic valves were identified in $60 \%(80 / 133)$ of patients in the ARR alone group and $56 \%(75 / 133)$ of patients in the ARR/hemiarch group $(P=.53)$.

\section{Propensity Score-Matched Groups: Operative Characteristics, Mortality, and Morbidity}

A bioprosthetic valve was used in $95 \%(126 / 133)$ of patients in the ARR alone group and in 89\% (119/133) of patients in the ARR/hemiarch group. The median (first quartile Q1, third quartile Q3) cardiopulmonary bypass time was 120.5 minutes $(91.0,158.5)$ in the ARR group versus 186 minutes $(150.0,229.0)$ in the ARR/hemiarch group $(P<.001)$. The median $(\mathrm{Q} 1, \mathrm{Q} 3)$ crossclamp time was 104 minutes $(82.0,137.0)$ for the ARR alone group versus 140 minutes $(116.5,170.0)$ for the ARR/hemiarch group $(P<.001)$. The median $(\mathrm{Q} 1, \mathrm{Q} 3)$ circulatory arrest time in the ARR/hemiarch group was 13 minutes (11.0, 16.0). Intraoperative blood product use remained lower after matching in the ARR alone group, with $51 \%$ $(68 / 133)$ of patients receiving blood products versus $67 \%$ (89/133) of patients in the ARR/hemiarch group $(P=.009)$. However, there was no difference in the average units of red blood cells, fresh-frozen plasma, cryoprecipitate, or platelets transfused between groups. Operative and 30-day mortality were $1.5 \%$ (2/133 patients) in the ARR alone group and $3.0 \%$ (4/133) in the ARR/hemiarch group $(P=.41)$. Patients in the ARR alone group who died had postoperative cardiac failure, 
1 requiring mechanical support who ultimately had care withdrawn, and the other had a cardiac arrest. In the ARR/hemiarch group, 2 deaths were due to sepsis and subsequent multisystem organ failure (1 had a terminal cardiac arrest, and 1 had a cardiac arrest and irreversible neurologic injury while at a rehabilitation facility). Medium-term overall survival was not significantly different (Figure 3, B) (log-rank $P=.24$ ) between the ARR alone $(91.4 \%, 95 \% \mathrm{CI}$ at 5 years, 85.8-96.9) and the ARR/hemiarch $(88.0 \%, 95 \% \mathrm{CI}$ at 5 years, $81.9-94.0)$ groups.

Postoperative complications are listed in Table 3. There was no difference in reoperation for bleeding between the 2 groups (10\% ARR alone vs $11 \%$ ARR/hemiarch; $P=.84)$. The postoperative stroke rate was $4.5 \%(6 / 133)$ in the ARR alone group and $2.3 \%(3 / 133)$ in the ARR/hemiarch group $(P=.31)$. Three patients $(2.3 \%)$ in the ARR alone group and 2 patients $(1.5 \%)$ in the ARR/hemiarch group developed acute renal failure that required temporary hemodialysis $(P=.65)$. There was no significant difference in hospital length of stay (median 6 days in both groups, $P=.5$ ) or total ICU length of stay (median 29.4 hours ARR/hemiarch vs 31.6 hours ARR alone, $P=.91$ ). There was no difference in the number of patients who received blood products postoperatively $(41 \%, 54 / 133$ vs $47 \%, 62 / 133, P=.32)$ between the matched groups. Although there remained no difference in units of red blood cells, plasma, or platelets transfused after matching, there was still a significant difference in units of cryoprecipitate transfused in the ARR alone versus ARR/hemiarch groups $(0.3 \pm 0.7$ vs $1.2 \pm 3.3, P=.045)$.

\section{Reoperation After Aortic Root Replacement}

Six patients from the overall cohort subsequently underwent reoperation after discharge for aortic or valve pathology after a prior ARR or ARR/hemiarch. Two patients $(2 / 207,1.0 \%)$ in the ARR group required reoperation, 1 for subacute bacterial endocarditis and 1 for structural valve dysfunction. Four patients who received ARR/hemiarch $(4 / 177,2.3 \%)$ underwent reoperation-2 for subacute bacterial endocarditis, 1 for structural valve dysfunction, and 1 for an aortic leaflet tear. All patients survived reoperation. The overall rate of reoperation for the ARR alone and ARR/hemiarch groups was $0.29 \% /$ person-year and $0.60 \% /$ person-year, respectively, and this difference was not significant $(P=.66)$. There were no reoperations in follow-up for subsequent progression of an aortic aneurysm in either group.

\section{DISCUSSION}

ARR using the modified Bentall procedure is recommended for aortic aneurysms involving the aortic root with aortic valve disease. A composite valve graft (valved conduit) is used in the setting of aortic root or ascending aorta aneurysms with aortic valve disease to accomplish the following: limit the progression of aneurysm, restore aortic valve function, improve distal blood flow particularly to the aortic arch vessels, and prevent the development of aortic dissection or rupture. ${ }^{11}$ However, if the aneurysmal lesion extends into the aortic arch, then a concomitant arch procedure (hemiarch or total arch replacement) becomes necessary. In patients with a surgically treated aortic aneurysm, a significant predictor of late mortality is complications of residual aortic aneurysmal disease or the development of an additional aortic aneurysm. ${ }^{12}$ Persistence of aortic aneurysm despite proximal repair often mandates a subsequent reoperation, and prior aortic root or ascending aorta surgery confers increased operative risk at the time of reoperation. ${ }^{13-16}$ The indications for reoperative aortic surgery include progressive enlargement of the remaining dissected aorta, graft infection, aortic valve insufficiency, development of false aneurysm, and aortic rupture. ${ }^{15,17}$ The addition of an aggressive approach involving hemiarch reconstruction at the time of initial operation is a source of debate because many patients who undergo ARR alone may never develop further progression of aortopathy. ${ }^{7,17}$ This study showed that ARR with the addition of a hemiarch reconstruction for proximal aortic arch diameter $4.0 \mathrm{~cm}$ or greater at the index operation did not confer any additional risk.

The decision to perform a hemiarch replacement must be considered carefully because of the technical challenges associated with aortic arch surgery and the risk of complications associated with DHCA. ${ }^{18}$ DHCA has been reported to be associated with hypothermia-induced coagulopathy, neuronal dysfunction and injury, endothelial dysfunction, and increased risk of organ dysfunction. ${ }^{6,19-21}$ The median circulatory arrest time in our series was 13 minutes, well within the "safe" window of operation of 25 to 50 minutes during hypothermic arrest. ${ }^{4-6,22}$ There was no significant difference in postoperative stroke rate between groups.

The addition of a hemiarch replacement using DHCA to ARR did not significantly increase stroke, bleeding, or infectious complications between our propensity-matched groups. There was no difference in operative or midterm all-cause mortality at 5-year follow-up. Resection of all diseased aortic wall aneurysms at the initial operation potentially reduces the need for future aortic intervention. In our series, only $1.0 \%$ of patients in the ARR alone group required reoperation in follow-up and $2.3 \%$ had a reoperation in the ARR/hemiarch group, with no difference in the rate of reoperation at $0.29 \% /$ person-year and $0.60 \% /$ person-year, respectively. However, our data are limited by short follow-up time. In their series of 142 patients who underwent ARR, Zehr and colleagues ${ }^{23}$ describe an overall freedom from reoperation of $96 \%$ at 5 years. Etz and colleagues ${ }^{24}$ followed 597 patients after composite mechanical or biological valved conduits and 
found an overall rate for valve or ascending aorta reoperation of $1.54 \%$ /person-year (6 in 3896 personyears). ${ }^{24}$ Hemiarch replacement can be associated with a low reoperation rate for aortic arch aneurysm. ${ }^{25}$ Indeed, no patients in our ARR/hemiarch group or the ARR alone group underwent subsequent reoperation for an aneurysm.

\section{Study Limitations}

This is a retrospective review of a prospectively collected single-center database and includes experienced surgeons, thus potentially limiting the generalizability. Our institution is a large referral center for complex aortic surgery. We have extensive experience in both aortic arch replacement and hemiarch procedures. These results should be applied only at institutions with the expertise and experience to perform hemiarch replacement safely. The average follow-up in this series is relatively short at 3.8 years in the ARR alone group and 4.8 years in the ARR/hemiarch group. This does provide midterm results and includes our entire experience at this institution. Longer-term follow-up will be needed to determine the rate of reoperation on the aorta.

\section{CONCLUSIONS}

The addition of the hemiarch is a safe strategy to avoid disease progression in the distal ascending aorta or proximal aortic arch and should be considered at the time of ARR. Ignoring aortic arch pathology during ARR could lead to complications from residual disease at the proximal aortic arch. Our study found no difference in operative mortality, midterm all-cause mortality, or significant morbidity with the addition of a hemiarch reconstruction to ARR.

\section{Conflict of Interest Statement}

S.C. Malaisrie reports consulting fees for Edwards, Bolton, and Baxter and lecture fees from Abiomed. All other authors have nothing to disclose with regard to commercial support.

\section{References}

1. Moon MR, Sundt TM III, Pasque MK, Barner HB, Huddleston CB, Damiano RJ Jr, et al. Does the extent of proximal or distal resection influence outcome for type A dissections? Ann Thorac Surg. 2001;71:1244-50.

2. Dossche KM, Tan ME, Schepens MA, Morshuis WJ, de la Riviere AB. Twenty-four year experience with reoperations after ascending aortic or aortic root replacement. Eur J Cardiothorac Surg. 1999;16:607-12.

3. Ehrlich MP, Ergin MA, McCullough JN, Lansman SL, Galla JD, Bodian CA, et al. Predictors of adverse outcome and transient neurological dysfunction after ascending aorta/hemiarch replacement. Ann Thorac Surg. 2000;69:1755-63.

4. Ergin MA, Griepp EB, Lansman SL, Galla JD, Levy M, Griepp RB. Hypothermic circulatory arrest and other methods of cerebral protection during operations on the thoracic aorta. J Card Surg. 1994;9:525-37.

5. Reich DL, Uysal S, Sliwinski M, Ergin MA, Kahn RA, Konstadt SN, et al. Neuropsychologic outcome after deep hypothermic circulatory arrest in adults. $J$ Thorac Cardiovasc Surg. 1999;117:156-63.

6. Wilde JT. Hematological consequences of profound hypothermic circulatory arrest and aortic dissection. J Card Surg. 1997;12:201-6.

7. Crawford ES, Kirklin JW, Naftel DC, Svensson LG, Coselli JS, Safi HJ. Surgery for acute dissection of ascending aorta. Should the arch be included? J Thorac Cardiovasc Surg. 1992;104:46-59.
8. Hiratzka LF, Bakris GL, Beckman JA, Bersin RM, Carr VF, Casey DE Jr, et al. 2010 ACCF/AHA/AATS/ACR/ASA/SCA/SCAI/SIR/STS/SVM guidelines for the diagnosis and management of patients with Thoracic Aortic Disease: a report of the American College of Cardiology Foundation/American Heart Association Task Force on Practice Guidelines, American Association for Thoracic Surgery, American College of Radiology, American Stroke Association, Society of Cardiovascular Anesthesiologists, Society for Cardiovascular Angiography and Interventions, Society of Interventional Radiology, Society of Thoracic Surgeons, and Society for Vascular Medicine. Circulation. 2010;121:e266-369.

9. Rinewalt D, McCarthy PM, Malaisrie SC, Fedak PW, Andrei AC, Puthumana JJ, et al. Effect of aortic aneurysm replacement on outcomes after bicuspid aortic valve surgery: validation of contemporary guidelines. J Thorac Cardiovasc Surg. 2014;148:2060-9.

10. Austin PC. Balance diagnostics for comparing the distribution of baseline covariates between treatment groups in propensity-score matched samples. Stat Med. 2009;28:3083-107.

11. Zierer A, Voeller RK, Hill KE, Kouchoukos NT, Damiano RJ Jr, Moon MR. Aortic enlargement and late reoperation after repair of acute type A aortic dissection. Ann Thorac Surg. 2007;84:479-87.

12. Crawford ES, Coselli JS, Svensson LG, Safi HJ, Hess KR. Diffuse aneurysmal disease (chronic aortic dissection, Marfan, and mega aorta syndromes) and multiple aneurysm. Treatment by subtotal and total aortic replacement emphasizing the elephant trunk operation. Ann Surg. 1990;211:521-37.

13. Crawford ES, Svensson LG, Coselli JS, Safi HJ, Hess KR. Surgical treatment of aneurysm and/or dissection of the ascending aorta, transverse aortic arch, and ascending aorta and transverse aortic arch. Factors influencing survival in 717 patients. J Thorac Cardiovasc Surg. 1989;98:659-74.

14. Etz CD, Plestis KA, Homann TM, Bodian CA, Di Luozzo G, Spielvogel D, et al. Reoperative aortic root and transverse arch procedures: a comparison with contemporaneous primary operations. J Thorac Cardiovasc Surg. 2008;136: 860-7, 867 e861-3.

15. Silva J, Maroto LC, Carnero M, Vilacosta I, Cobiella J, Villagran E, et al. Ascending aorta and aortic root reoperations: are outcomes worse than first time surgery? Ann Thorac Surg. 2010;90:555-60.

16. Kirsch EW, Radu NC, Mekontso-Dessap A, Hillion ML, Loisance D. Aortic root replacement after previous surgical intervention on the aortic valve, aortic root, or ascending aorta. J Thorac Cardiovasc Surg. 2006;131:601-8.

17. Luciani N, De Geest R, Anselmi A, Glieca F, De Paulis S, Possati G. Results of reoperation on the aortic root and the ascending aorta. Ann Thorac Surg. 2011;92: 898-903.

18. Livesay JJ, Cooley DA, Reul GJ, Walker WE, Frazier OH, Duncan JM, et al. Resection of aortic arch aneurysms: a comparison of hypothermic techniques in 60 patients. Ann Thorac Surg. 1983;36:19-28.

19. Tian DH, Wan B, Bannon PG, Misfeld M, Lemaire SA, Kazui T, et al. A meta-analysis of deep hypothermic circulatory arrest alone versus with adjunctive selective antegrade cerebral perfusion. Ann Cardiothorac Surg. 2013;2:261-70.

20. Kamiya H, Hagl C, Kropivnitskaya I, Bothig D, Kallenbach K, Khaladj N, et al. The safety of moderate hypothermic lower body circulatory arrest with selective cerebral perfusion: a propensity score analysis. J Thorac Cardiovasc Surg. 2007; 133:501-9.

21. Cooper WA, Duarte IG, Thourani VH, Nakamura M, Wang NP, Brown WM III, et al. Hypothermic circulatory arrest causes multisystem vascular endothelial dysfunction and apoptosis. Ann Thorac Surg. 2000;69:696-703.

22. Svensson LG, Crawford ES, Hess KR, Coselli JS, Raskin S, Shenaq SA, et al. Deep hypothermia with circulatory arrest. Determinants of stroke and early mortality in 656 patients. J Thorac Cardiovasc Surg. 1993;106:19-31.

23. Zehr KJ, Orszulak TA, Mullany CJ, Matloobi A, Daly RC, Dearani JA, et al. Surgery for aneurysms of the aortic root: a 30-year experience. Circulation. 2004;110:1364-71.

24. Etz CD, Bischoff MS, Bodian C, Roder F, Brenner R, Griepp RB, et al. The Bentall procedure: is it the gold standard? A series of 597 consecutive cases. J Thorac Cardiovasc Surg. 2010;140:S64-70; discussion S86-91.

25. Rylski B, Milewski RK, Bavaria JE, Vallabhajosyula P, Moser W, Szeto WY, et al. Long-term results of aggressive hemiarch replacement in 534 patients with type A aortic dissection. J Thorac Cardiovasc Surg. 2014;148:2981-5.

Key Words: aortic aneurysm, aortic root replacement, Bentall, hemiarch 

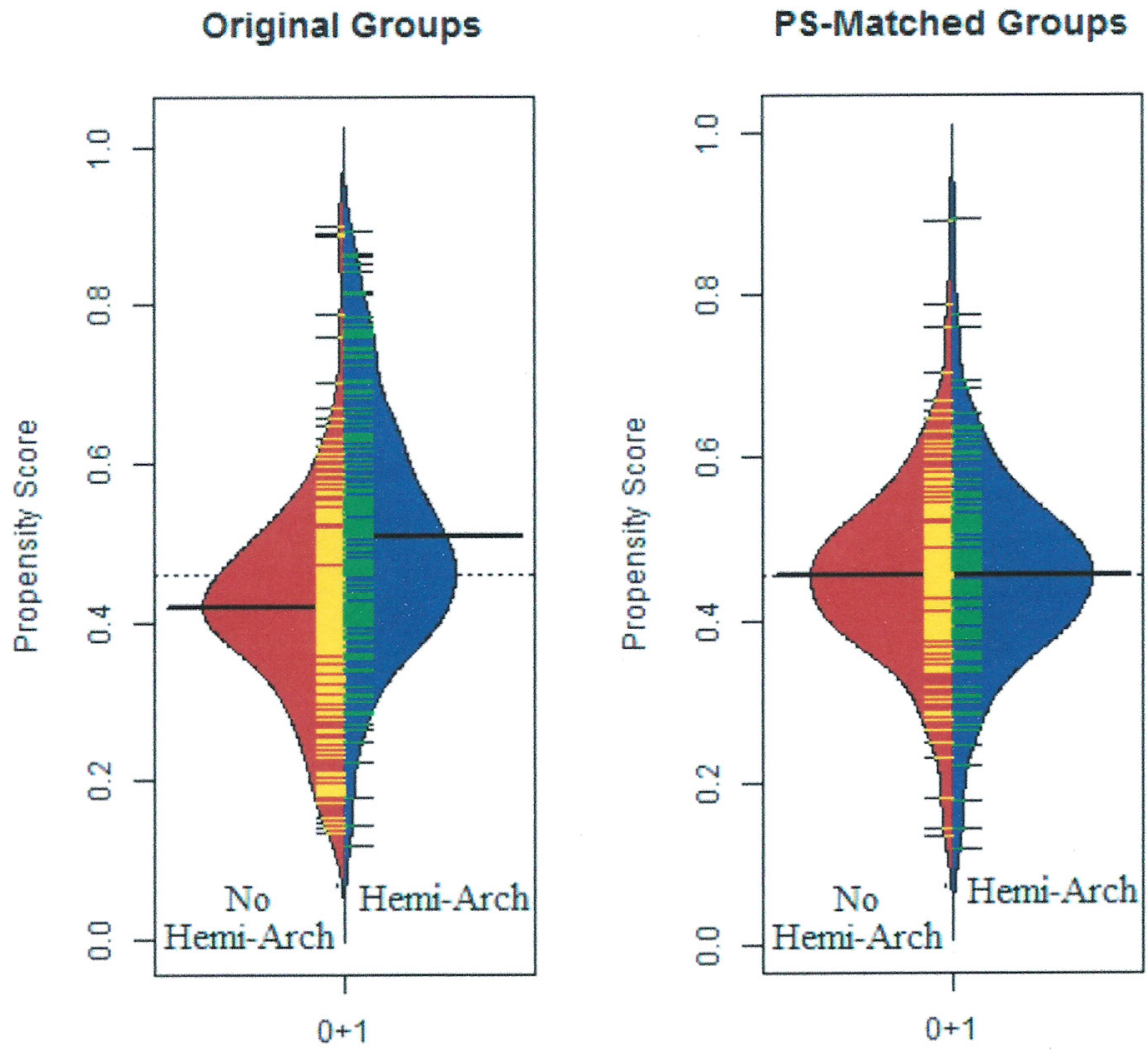

FIGURE E1. Beanplots (kernel-smoothed histograms) of the PS in the original and PS-matched groups. PS, Propensity score. 
TABLE E1. Standardized differences of original and propensity score-matched groups

\begin{tabular}{|c|c|c|}
\hline \multirow[b]{2}{*}{ Variable } & \multicolumn{2}{|c|}{ Standardized difference } \\
\hline & $\begin{array}{c}\text { Original } \\
\text { groups }\end{array}$ & $\begin{array}{l}\text { PS-matched } \\
\text { groups }\end{array}$ \\
\hline Age (y) & 0.20008 & -0.10078 \\
\hline BSA & -0.07686 & -0.02081 \\
\hline Body mass index & -0.10217 & -0.07665 \\
\hline Ambler score & 0.17536 & -0.01897 \\
\hline Female & 0.12248 & -0.05463 \\
\hline CAD & 0.06746 & -0.00646 \\
\hline Family history of CAD & 0.10632 & 0.00000 \\
\hline Diabetes & -0.12114 & -0.05250 \\
\hline Hypercholesterolemia & 0.05573 & 0.01515 \\
\hline Hypertension & 0.15406 & -0.06146 \\
\hline Prior MI & 0.08586 & 0.07912 \\
\hline COPD & 0.02731 & 0.11424 \\
\hline CVD & -0.11607 & 0.10476 \\
\hline CVA & 0.05845 & 0.03777 \\
\hline Prior CABG & 0.08708 & -0.14126 \\
\hline Prior valve surgery & 0.01519 & 0.00000 \\
\hline Prior CV intervention & 0.12851 & 0.09293 \\
\hline Prior CHF & -0.04226 & -0.07827 \\
\hline NYHA functional class III or IV & 0.19825 & -0.06250 \\
\hline Angina & 0.22580 & -0.06738 \\
\hline Preoperative beta-blockers & 0.11769 & 0.00000 \\
\hline Preoperative statins & 0.11420 & 0.00000 \\
\hline Aortic stenosis & 0.09514 & -0.04174 \\
\hline Repeat sternotomy & 0.03260 & 0.00000 \\
\hline MV surgery & -0.11518 & -0.04159 \\
\hline CABG & 0.15461 & 0.02043 \\
\hline AF ablation surgery & -0.07331 & -0.02675 \\
\hline Elective status & -0.12499 & 0.06328 \\
\hline
\end{tabular}

$P S$, Propensity score; $B S A$, body surface area; $C A D$, coronary artery disease; $M I$, myocardial infarction; $C O P D$, chronic obstructive pulmonary disease; $C V D$, cardiovascular disease; $C V A$, cerebrovascular accident; $C A B G$, coronary artery bypass grafting; $C V$; cardiovascular; $C H F$, congestive heart failure; $N Y H A$, New York Heart Association; $M V$, mitral valve; $A F$, atrial fibrillation. 